\title{
МОЖЕТ ЛИ СТАТЬ МЕТАРЕАЛИСТСКИЙ ТЕКСТ ПРИВЛЕКАТЕЛЬНЫМ ДЛЯ СТУДЕНТОВ ВУЗА?
}

\author{
Андреа Громинова \\ CAN A METAREALISTIC TEXT BECOME ATTRACTIVE TO UNIVERSITY \\ STUDENTS?
}

\begin{abstract}
Andrea Grominová
Резюме: Поэзия метареализма считается поэзией сложности восприятия, толкования, понимания не только для студентов, а также для самих исследователей и литературных критиков. Богатое использование метаметафор, или же метабол, и их последовательное накапливание затрудняет декодирование отдельных образов и смысл всего стихотворения. Поэтические тексты такого рода, кроме того, требуют от своего читателя общего кругозора знаний по истории, культуре, литературе, технике и т.д. Расшифровка смысла нередко напоминает разгадывание кроссвордов. Чтобы мотивировать студентов вузов, изучающих русский язык как иностранный, читать и понимать поэзию метареализма, нужно вызвать интерес у них. Поэтому цель нашего доклада мы определили так - показать разнообразное использования информационных технологий на занятиях по русской литературе, а конкретнее на семинарах по современной русской литературе для привлечения внимания к метареалистской поэзии.
\end{abstract}

Ключевые слова: информационные технологии, семинар по современной русской литературе, анализ и интерпретация поэтического текста, метареализм.

\begin{abstract}
The poetry of metarealism is considered the poetry of the complexity of perception, interpretation, understanding, not only for students, but also for the researchers and literary critics themselves. The rich use of metametaphors, or the metabol, and their sequential accumulation makes it difficult to decode individual images and the meaning of the whole poem. Poetic texts of this kind, in addition, require their readers to have a general outlook on knowledge of history, culture, literature, technology, etc. Deciphering the meaning often resembles solving crosswords. To motivate university students studying Russian as a foreign language to read and understand the poetry of metarealism, one needs to arouse interest among them. Therefore, the purpose of this paper is to show the diverse use of information technology in the classroom on Russian literature, and more specifically in seminars on modern Russian literature to draw attention to metarealist poetry.
\end{abstract}

Key words: information technology, a seminar on modern Russian literature, analysis and interpretation of a poetic text, metarealism.

DOI: $10.14712 / 9788076032088.6$

Преподаватели вузов нередко сталкиваются с проблемой «нечтения» и непонимания поэзии студентами. Можно констатировать, что у учащихся отсутствует навык чтения поэтических текстов, поэтому преподавателю приходится бороться с этим фактом на семинарах по интерпретации художественных текстов. Перед ним стоят главные вопросы: Как заинтересовать студента прочитать поэтический текст? Как его мотивировать? Как сделать занятие настолько занимательным, чтобы студент сам, без принуждения, стал 
больще читать поэзию в свое свободное время, ради удовольствия, не только чтобы выполнить домашнее задание? Найти ответы на эти вопросы и осуществить данные задачи - не просто. В нашей статье мы попытаемся показать один из путей, который мы использовали на конкретном семинаре по интерпретации художественных текстов. Нужно уточнить, что семинар рассчитан для словацких студентов первого курса магистратуры по специальности Русский язык и культура в сфере делового общения. Приобретенные ранее теоретические знания по курсам Современная русская литература I и II студенты могут закрепить именно на этом семинаре. Несмотря на то, что семинар длится два семестра, у студентов (только) одно занятие в неделю, поэтому в начале каждого семестра преподавателю необходимо тщательно продумать выбор конкретных художественных текстов для анализа и интерпретации. Темой семинара, который мы попытаемся прокомментировать в данной статье, является поэзия метареализма, или же метаметафоризма. Главный объект анализа и интерпретации - стихотворение «Неоновый калейдоскоп» одного из основных представителей этой поэтической школы - Ивана Жданова.

До семинара студенты читают стихотворение в качестве домашнего задания, анезнакомые слова и выражения переводят на словацкий язык. В начале семинара преподаватель задает вопрос: Что Вы знаете об Иване Жданове? Студенты отвечают, а педагог записывает их ответы на доске. Один из студентов готовит краткий документальный фильм о Жданове, который показывает всей группе. Использование информационных технологий делает учащихся более сосредоточенными, внимательными и способствует развитию различных типов памяти. Их внимание не носит лишь созерцательный характер, оно призывает к действию реакции

на увиденное (Ермачкова - Хвалова 2020, 542). Новые сведения и интересные факты об авторе преподаватель дописывает на доске. Еще один студент показывает фотографию самого автора.

Начиная анализ стихотворения, не будет лишним, кроме сведений об авторе, повторить также отдельные знаки конкретного литературного направления или поэтической школы. Один студент демонстрирует презентацию о главных чертах метареализма, которую дополняет комментариями на занятии. Конечно, при этом он активно задает вопросы своим одногруппникам и проверяет, помнят ли они факты с лекции о метареализме, которая предшествовала этому семинару. Главной чертой мы считаем художественный метод представителей поэзии метареализма - необарокко, а главным средством выражения метаболу, или же метаметафору, “благодаря» которой очень сложно декодировать смысл, суть стихотворений.

Далее переходим к конкретному анализу текста «Неоновый калейдоскоп». Преподаватель сначала задает вопросы типа: Какое впечатление у Вас осталось после прочтения этого текста? Сможете ли вы определить его суть? Если да, сможете ли вы определить его одним словом? Если да, каким? Ответы студентов педагог опять записывает на доске, используя метод мозгового штурма, чтобы в конце семинара суммировать все и понять, уловили ли студенты смысл данного произведения. Студенты признаются, что проникнуть в суть стихотворения для них очень сложно из-за накапливания метабол (или же метаметафор) и авторского помещения слов и выражений из разных областей жизни в необыкновенные контексты, что мешает восприятию поэтических образов. Преподавателю всегда интересно, какие ответы на вышеуказанные вопросы он получит от студентов. Он даже может попросить каждого из них нарисовать картину впечатлений от прочтения стихотворения до совместного анализа на семинаре, а потом сравнить ее с картиной, нарисованной после совместного анализа. 
У студентов часто получаются две разные картины. Таким образом, можно раскрыть эмоциональное восприятие текстов учащимися и немножко заглянуть в их психику.

Задумаемся над названием стихотворения. Несмотря на то, что слово «калейдоскоп» всем нам хорошо известно, для уточнения значений этого слова мы обращаемся к «Большому толковому словарю современного русского языка» Д.Н. Ушакова (2006). Студент открывает словарь и зачитывает вслух информацию о происхождении слова калейдоскоп (от греческого kalos - «прекрасный», eidos - «вид» и skopeo - «смотрю») и его двух значениях: «1. Прибор в виде зрительной трубки с вставленными в нее под известным углом друг к другу зеркальными стеклами

и положенными между ними цветными стеклышками, отрезками цветной бумаги, бисером и т.п., которые при поворачивании прибора отражаются в зеркалах и создают разнообразные красивые узоры. 2. В переносном значении это быстрая смена мелькающих образов, впечатлений. К. лиц. Пестрый к. событий» (Ушаков 2006, 331).

Другой студент в том же словаре находит значение слова «неон». Он констатирует, что оно возникло от греческого слова neos, обозначает «новый», являет собой «химический элемент, один из так наз. благородных газов» (Там же, с. 529). У третьего студента в руках «Словарь русского языка» С.И. Ожегова, из которого он читает дополнительное толкование: неон - «инертный газ без цвета и запаха, в осветительных трубках и электрических лампах дающий красное свечение» (Ожегов 1981, 359). На основе этих толкований совместно со студентами мы подводим итог - это название для стихотворения автор выбрал неслучайно. Попытаемся доказать нашу догадку на основе анализа. Добровольно вызвавшийся студент читает вводные строки:

Вот и слово прошло по прокатному стану неона, сквозь двухмерную смерть и застыло багровой короной над пустым магазином, над потным челом мирозданья, нашатырной тоской проникая в потемки молчанья... (Жданов 1997, 59).

Уже в первой строке мы раскрываем одну из главных черт поэзии метареализма отсылку к излюбленному техническому миру, представленному здесь прокатным станом для обработки металлов. Студенты находят связь с профессией слесаря, которой Жданов занимался ранее. Об этом мы говорили в начале занятия и слышали данные факты в документальном фильме об авторе.

Все эти излюбленные авторами технические элементы в поэзии метареализма играют большую роль в декодировании художественной модели их поэтического мира, поэтому всегда хорошо остановиться при их объяснении. Один студент находит в Интернете толкование словосочетания «прокатный стан» вместе с информацией о том, что «первым человеком, изобразившим и описавшим принцип работы ручного прокатного стана, имевшего еще плоские валики, был Леонардо да Винчи в 1495 году» (Прокатный стан, онлайн). Потом он читает вслух все толкование: «В конце XVI века первыми появились деревянные прокатные станы. Между двумя железными валками вставляли одним концом нагретую до высокой температуры металлическую болванку, а затем начинали вращать крестовиной верхний валок. Болванка проходила между валками и сплющивалась. На таких станах прокатывали сначала свинцовые листы, идущие на изготовление органных труб, а затем стали прокатывать серебро и золото для чеканки монет» (там же). Если учитывать описанный процесс работы прокатного стана и связь 
с рядом стоящим «словом», которое «прошло... сквозь двухмерную смерть и застыло багровой короной // над пустым магазином, над потным челом мирозданья...", то можно догадаться, что речь идет о надписи, сияющей красным цветом над магазином.

На семинаре в руках у одного студента книга Ивана Жданова в соавторстве с М. Шатуновским «Диалог-комментарий пятнадцати стихотворений Ивана Жданова», в которой сам автор пытается открыть тайну некоторых своих стихов и «подсказывает» своим читателям, как можно понимать образы в его стихотворениях. На протяжении целого семинара учащийся читает из этой книги и, таким образом, помогает нам уловить суть. М. Шатуновский толкует «потное чело» как «образ трудящегося мироздания. Современная трансформация Иоанна Богослова: Бог дал человеку слово, а он сделал из него рекламу» (Жданов - Шатуновский 1997, 60). Опираясь на это изложение, «двухмерная смерть» может восприниматься как опустошение самого понятия “слово» (в рекламе), его деструкция (в этом месте упоминаем теорию Ж. Деррида), подчинение власти денег, а одновременно сопротивление Богу, Творцу всего мира, космоса. Кроме такого толкования, студенты обнаруживают и другую точку зрения на этот метафорический, или же метаболический образ, а именно: прокатный стан для обработки металлов может представлять собой машину, связанную с печатанием текстов, газет, книг, состоящих из слов. Так как кроме актуально анализированного текста у студентов был опыт прочтения и других стихотворений И. Жданова, это дает им возможность провести параллели с ними. В этом случае студенты находят связь со стихотворением «Рапсодия батареи отопительной системы» И. Жданова, где присутствует подобный метафорический, или же метаболический образ. Автор здесь использует линотип, предназначенный для отливки строк текста

в типографии из чугунного сплава. В более широком смысле, мы приходим к выводу, что в обоих случаях речь идет о слове, появление которого является результатом технического процесса. В этом можно увидеть одну из целей всех «метареалистов/метаметафористов» - возобновить слово путем его помещения в новую оболочку, новый контекст с помощью новых средств выражения, которыми являются «сверх-метафоры» или же «метаболы/метаметафоры», при этом опираясь на техно-лексику.

Преподаватель сосредоточится на слове как таковом. Задаст вопрос - какое литературное течение, направление или школа стремились к ясности образа и точности поэтического слова. Студенты наблюдают связь поэзии И. Жданова с поэзией акмеизма, вспоминают, что слово, по мнению акмеистов, должно было приобрести свой изначальный смысл, что А. Ахматовой и И. Мандельштаму удалось оставить после себя «вечные слова».

Вернемся опять к анализируемому стихотворению. Если магазин представляет собой мирозданье, т.е. весь космос, а слово в форме рекламы находится на уровень выше, мы предполагаем, что лирический субъект подчеркивает сегодняшнее неуважительное или даже пренебрежительное отношение к слову за счет материального обеспечения (прокатка серебра и золота для чеканки монет). Некоторые студенты это воспринимают как вызов современному человеку, чтобы задуматься над значением слова как такового, избежать его «смерти». Потом человечеству остается только молчание, на что лирический субъект и намекает в конце первой строфы. На основе следующих строк мы догадываемся, что «действие» стихотворения происходит ночью. Студент - доброволец читает вслух:

...И над желтой равниной зажженных свечей обгорают крылья вогнутых окон, и маковым громом играют 
две бумажных обертки на тронном полу магазина, ослепляя себя, как миражные пятна бензина.

Это каплю дождя, как бутон нераскрытой снежинки, электрический свет разрезает на две половинки, на две полых бумажки, как будто даровано право им себя выбирать и травиться двухмерной отравой... (Жданов 1997, 59).

Попытаемся толковать отдельные образы строк. Главное - представить их себе. Развернутый образ - «И над желтой равниной зажженных свечей обгорают // крылья вогнутых окон...» - студенты воспринимают как зажженные окна домов, свет которых отражается в окнах соседних зданий. Здесь отмечается превращение одного (одних окон) в другое (в другие, открытые окна). По их мнению, мотив свечения сохраняется и дальше, когда на «тронном полу магазина» (пустом ночью, обширном пространстве) в ветре шевелятся сияющие бумажные обертки, а также в случае электрического света, обладающего необычной способностью разрезать пополам каплю дождя на две бумажки. Студент открывает «Диалог-комментарий пятнадцати стихотворений Ивана Жданова» и мы узнаем, что сам Жданов в комментарии к этому стихотворению говорит об «ипостасях слова, умерщвленного двухмерностью» (Жданов - Шатуновский 1997, 60). В этом случае, по мнению студентов, имеется в виду то, что слово обладает двумя размерностями, а именно: каплю воды разрезать пополам физически невозможно. Но возможно это только при написании этого слова «капля» (или же слов «капля дождя») на бумаге, так как после разрезания получаются ее две половинки, и на каждой есть буквы, т.е. части слова (или же слов). Мы приходим к общему выводу, что И. Жданов считает «двухмерность» слова его отравой, путем к гибели слова. С другой точки зрения на анализируемый образ можно смотреть так - электрический свет как достижение техники или человека стремится преодолеть природу, замещенную каплей дождя, т.е. пытается сделать невозможное. Все мнения, идеи и расшифровки преподаватель постоянно записывает на доске.

В следующей строфе происходит смена темы. Преподаватель подчеркивает, что лирический субъект как бы смотрит фотографии из детства, расплывчато вспоминая уловленный момент. Студент читает строфу:

...И по желтому полю, по скошенным травам наследства

желтизной фотографий восходит размытое детство

в заоконное небо, мерцая прямыми углами -

море в жилы вошло и замкнулось в обугленной раме... (Жданов 1997, 59).

Студенты сразу декодируют мотивы окна и зеркала - любимые мотивы И. Жданова, тесно связанные с моральными вопросами, совестью, углублением во внутренний мир человека. Один студент обнаруживает мотив окна в выражении «заоконное небо», куда направлено воспоминание о времени детства. Другой - высказывает предположение, что зеркало представляет собой взгляд лирического субъекта в глубину самого себя, что отражается в направлениях от «Я» к «внутри меня» и наоборот; окно - взгляд в направлении - от «меня, моего Я» к «внешнему миру». Кажется, что лирический субъект хочет поделиться своими воспоминаниями с внешним миром посредством описания впечатлений от фотографии на фоне своих стихов. 
В следующих строках опять происходит смена темы. Слушаем:

...Плачут деньгами толпы, доносится музыка злая, словно огненный бык здесь мочой наследил, ковыляя, словно плачет по гриве, по конскому волосу лента.

А пустой магазин одинок посреди континента.

O, ночной магазин, в неподвижные двери экстаза

ты впускаешь меня и едва замечаешь вполглаза, что отвесный прибой из замочных разодранных скважин еле виден тебе - он как будто неровен и влажен... (Жданов 1997, 59).

От воспоминаний лирический субъект движется к вопросу денег в жизни человека. Иван Жданов иронично (ирония студентами замечается благодаря употреблению слова «моча») подчеркивает, как люди гонятся за деньгами, за «гарантией» лучшей жизни, чтобы избежать материального недостатка, не осознавая, что это путь к их гибели. Наряду с этим, студенты находят толкование использованного автором мотива «огненного быка», который связан с восточной астрологией, а по китайскому гороскопу он обозначает властную личность, часто достигающую власти, денег и славы (Огненный Бык. Типы быков по восточному гороскопу, онлайн).

Для истолкования этих строчек приводим также мнение М. Шатуновского, полагающего, что (читаем из «Диалога-комментария»): «если магазин - мироздание, то он - это воплощенная заброшенность жизни на земле, посреди бесконечного космоса, оторванность, затерянность среди мертвой материи, то есть, в сущности, - одиночество человека в одиноком мироздании... Все-таки здесь магазин - уменьшенная копия мироздания среди толп поколений, сменяющих друг друга, как волны... И магазин сквозь свои скважины видит эти толпы, эти волны, прибои, приливы и отливы, наблюдает вековечные ежесуточные временные циклы» (Жданов Шатуновский 1997, 61). Задумываясь над анализом этого стихотворения, можно утверждать, что с его мнением мы согласны. Добавим, что «пустой магазин одинок посреди континента» может также представлять собой человека со своим «ассортиментом товара» (своим внутренним миром), чувствующего себя одиноким, может быть, «потерянным» или же чужим среди других людей. Студенты уточняют, что лирический субъект обращается к «ночному магазину» вселенной и говорит о своем состоянии экстаза при входе в него, чувствует себя составной частью - микрокосмосом этого большого, бесконечного макрокосмоса; или же он обращается к самому себе, так как только ночью перед ним открываются вопросы, терзающие его душу. В этом аспекте студенты почувствовали связь с постромантической поэзией Ф.И. Тютчева, воспринимающего мир сквозь призму хаоса, в котором все родилось и все гибнет. Они констатируют, что Ф. Тютчев, так же как и И. Жданов, часто изображал хаос ночью, когда перед его лирическим субъектом обнажались тайны сотворения и существования человека, природы, мира и космоса. Далее уточняют: Ф. Тютчев полагал, что слияние с этим первоначальным бытием привлекает человека, потому что обеспечивает ему бессмертность, но одновременно его и пугает, так как в этом анонимном первобытии он теряет свою идентичность. Это и сказывалось на постоянной борьбе лирического субъекта Ф. Тютчева с собственным «Я».

В последних строфах обнаруживаем И. Жданова не только как поэта, но и как фотографа, который опять возвращается к «перепаханному слову», к его двухмерности: 
...Это гладь фотоснимка сырыми дождями размыло, это желтое поле пластами себя развалило.

Перепахано слово. И, твой зачарованный пленник, не озноб и не страх - я держу на горбу муравейник.

Две бумажки твои догорят, задыхаясь от вони, по прилавкам твоим разбредутся быки или кони.

И, неоновой кровью и деньгами в прах истекая, беспробудные толпы замрут, как тоска городская.

Но нельзя подчиниться, чему еще можно открыться. На оттаявший голос поднимутся скорбные лица.

И засохнет, как кровь, посреди шевелящихся денег так похожий на твердь и на черный пейзаж муравейник (Жданов 1997, 59).

Преподаватель комментирует, что слово и фотографию объединяет размытость во времени. Лирический субъект, по его мнению, воплощен в позиции «зачарованного пленника» космоса, держащего на горбу муравейник. Напоминает, что о муравейнике писал еще Аристотель, и спрашивает студентов, что такое муравейник. Все их ответы и замечания появляются на доске. Преподаватель суммирует, что муравейник представляет собой практически полный аналог, или же прообраз человеческого общества: он, так же как и человеческое общество, сложно организован, в нем существуют $и$ разделение труда, $и$ специализация, и свой язык, на котором «разговаривают» муравьи и т.д. (Муравьиные мегаполисы, онлайн). С этой точки зрения учащиеся предполагают, что лирический субъект (или поэт?) чувствует себя ответственным за судьбу человечества и за судьбу слова и призывает читателей своих стихов "не подчиняться», вернуть слову его значение, избавиться от смуты, потому что надежда все еще есть. Преподаватель добавляет, что этот вопрос автор решает и в других стихотворениях, например, «До слова», «Взгляд» и др.

Возвращаясь к выше приведенному толкованию слова «калейдоскоп», преподаватель со студентами подводят итог, что его переносное значение («быстрая смена мелькающих образов, впечатлений») абсолютно применимо к тексту стихотворения. В каждой из девяти строф автор пользовался богатой сменой всякого рода деталей, причем получались новые образы, ассоциации, впечатления, непривычные сочетания вещей или явлений. Таким понятием «калейдоскоп» - в некоторой степени мы определяем характер поэзии Жданова в целом.

После анализа и интерпретации стихотворения преподаватель просит студентов опять нарисовать свои впечатления от художественного текста, а затем каждый студент сможет сравнить оба рисунка - до совместного анализа на семинаре и после него. На рисунках большинства студентов отмечаются различия в восприятии данного текста. Это тоже свидетельствует о необходимости тщательно продумывать процесс анализа и интерпретации поэтических (а особенно сложных, трудных для понимания) текстов преподавателем, чтобы активировать их мысль к декодированию отдельных метабол, их накапливанию и не потеряться в этой цепочке.

На основе более детального описания этого семинара мы попытались показать вклад каждого из студентов в занятие. Самостоятельная работа очень важна в учебном процессе, 
иногда «преподаватель должен отойти на второй план, предоставляя своим ученикам возможность самообучения, получения новых знаний и формирования умений на основе уже освоенных» (Догнал - Гаярски 2018, 66). В ходе данного семинара нам удалось хорошо распределить роли: один студент подготовил документальный фильм об авторе, второй презентацию по метареализму, третий - получил ключевую книгу «Диалог-комментарий пятнадцати стихотворений Ивана Жданова», из которой читал отрывки к рассматриваемому тексту. Некоторые студенты читали строфы стихотворений, искали определения в толковых словарях, печатных изданиях и в Интернете и т.д. Но главное - несмотря на их роли, все пытались расшифровать отдельные поэтические образы, определить систему образности, а затем художественную модель мира в метареалистской поэзии Ивана Жданова. Расшифровка часто напоминала нам решение кроссвордов, потому что кроме более детального толкования технических достижений мы находили связь с представителем русской постромантической поэзии Ф.И. Тютчевым, а также - с акмеизмом. В конце семинара преподаватель показывал студентам фотографии И. Жданова, на которых студенты смогли найти некоторые черты, переплетающиеся с его поэзией.

На основе вышесказанного можно утверждать, что семинары по анализу и интерпретации поэтических текстов современных русских авторов могут привлекать внимание студентов вузов, быть для них интересными, обогащать их новыми взглядами на окружающий мир и мотивировать к признанию поэзии как составной части искусства.

\section{Использованная литература/ References}

\section{Печатные источники:}

ДОГНАЛ, Й., ГАЯРСКИ, Л. (2018): Влияет ли знание грамматики на продуктивные речевые способности студентов-русистов? (на примере одного опроса и словацких студентов). In Filologičeskij klass. Н. 4(54) (2018). С. 65-71. ISSN 2071-2405.

ЖДАНОВ, И. - ШАТУНОВСКИЙ, М. (1997): Диалог-комментарий пятнадиати стихотворений Ивана Жданова. Москва: Издательство университета истории культур, 1997. 88 с. ISBN 5-89865-003-2.

ЖДАНОВ, И. (1997): Неоновый калейдоскоп. In: Диалог-комментарий пятнадцати стихотворений Ивана Жданова. Москва: Издательство университета истории культур, 1997. 88 с. ISBN 5-89865-003-2.

IERMACHKOVA, O., CHVALOVA, K. (2020): Role of Digital Technologies in the Foreign Language Classroom. In Proceedings of the International Scientific Conference "Digitalization of Education: History, Trends and Prospects" (DETP 2020). Volume 437. Paris: Atlantis Press, 2020. Pp. 542-547. ISBN 978-94-6252-965-6.

ОЖЕГОВ, С.И. (1981): Неон. In: Словарь русского языка. Москва: Издательство Русский язык, 1981. 815 с. УШАКОВ, Д.Н. (2006): Калейдоскоп. In: Большой толковый словарь современного русского языка. 180000 слов и словосочетаний. Москва: Альта-Принт, 2006. 1239 с. ISBN 5-98628-044-Х 217.

УШАКОВ, Д.Н. (2006): Неон. In: Большой толковый словарь современного русского языка. 180000 слов и словосочетаний. Москва: Альта-Принт, 2006. 1239 с. ISBN 5-98628-044-Х 217.

\section{Онлайн-источники:}

Муравьиные мегаполисы (онлайн). In Социология - Антропология. Этнография. [онлайн]. Режим доступа: http://texts.news/antropologiya-etnografiya_1383/muravinyie-megapolisyi67055.html [дата обращения: 2020-05-06].

Огненный Бык. Типы быков по восточному гороскопу (онлайн). In Восточная астрология. [онлайн]. Режим доступа: http://geocult.ru/kitayskaya-astrologiya/tipyi-byikov-po-kitayskomu-goroskopu [дата обращения: 2020-05-06]. 
Прокатный стан (онлайн): mirnovogo.ru. Мир великих открытий [онлайн]. Режим доступа: http://mirnovogo.ru/prokatnyj-stan [дата обращения: 2020-05-06].

ДАННАЯ СТАТЬЯ ПОДГОТОВЛЕНА В РАМКАХ ПРОЕКТА KEGA С̌. 021UCM-4/2020 S NÁZVOM TVORBA UČEBNÍC PRE RUSKOSLOVENSKÉ SEKCIE BILINGVÁLNYCH A SLOVANSKÝCH GYMNÁZIÍ.

\section{Профиль автора:}

Андреа Громинова, заведующая кафедрой русистики ФФ Университета им. Св. Кирилла и Мефодия в г. Трнаве, Словакия, доцент, кандидат философских наук

Научные интересы: русская поэзия XIX-XXI вв., рефлексия русской литературы в словацком культурном контексте

e-mail: andrea.grominova@ucm.sk

Место работы: Университет им. Св. Кирилла и Мефодия в г. Трнаве, философский факультет, пл. Й. Херду, д. 2, 91701 Трнава, Словакия

\section{Author's profile:}

doc. PhDr. Andrea Grominová, PhD., Head of the Department of Russian Studies, Faculty of Arts, University of Ss. Cyril and Methodius in Trnava

Research interests: Russian poetry of the XIX-XXI centuries, a reflection of the Russian literature in the Slovak cultural context

e-mail: andrea.grominova@ucm.sk

Place of work: University of Ss. Cyril and Methodius in Trnava, Nám. J. Herdu 2, 917 01, Trnava, Slovakia 